\title{
Erişkin hastada dev servikal kistik lenfanjiom: Olgu sunumu
}

\author{
Giant cervical cystic lymphangioma in adult patient: Case report \\ Ozan Erol@, Alper Köycü $@$, Erdinç Aydın (1) \\ Başkent Üniversitesi Tip Fakültesi, Kulak Burun Boğaz Anabilim Dall, Ankara, Türkiye
}

\begin{abstract}
$\ddot{O} Z$
Lenfanjiomlar genel olarak iki yaş altında görülen, lenfatik kanalları etkileyen benign karakterli doğuştan malformasyonlardır. En sık baş ve boyun bölgesinden köken alırlar. Erişkin yaşta görülmesi nadir olmakla birlikte servikal kitlelerde ayırıcı tanıda akılda tutulmalıdır. Öykü, fizik muayene bulguları ve görüntüleme yöntemleri yoluyla tanı konulur. Tercih edilen tedavi yöntemi cerrahidir. Bu yazıda, sol servikal bölgede bulunan ve daha önce eksize edilmesine rağmen büyümeye devam eden $13.2 \times 7.6 \times 13 \mathrm{~cm}$ boyutlarında kitlesi olan 27 yaşında bir erkek hasta sunuldu. Kitlenin ultrasonografi ve manyetik rezonans görüntüleme bulguları kistik lenfanjiom ile uyumlu idi. Dolayısıyla, kitlenin tamamı eksize edildi. Histopatolojik inceleme kistik lenfanjiom ile uyumlu idi. Cerrahi sonrası dönemde komplikasyon izlenmedi ve bir yıllık takipte nüks gelişmedi.
\end{abstract}

Anahtar sözcükler: Erişkin; servikal; kistik lenfanjiom.

Lenfanjiomlar lenfatik sistemin nadir görülen doğuştan proliferasyonudur. Tanı sıklıkla çocukluk yaşlarında konulur. Erişkinlerde oldukça nadirdir. Baş ve boyun bölgesi en sık köken aldıkları yerlerdir. ${ }^{[1,2]}$ Baş ve boyun lenfanjiyomları sıklıkla boyun, oral kavite mukozal yüzeyi ve özellikle dilde yerleşim gösterir. ${ }^{[3]}$ Tedavide ise tercih edilen ana yöntem total eksizyondur. ${ }^{[1-3]}$

$\mathrm{Bu}$ yazıda, daha önce ameliyat edilen fakat aynı bölgede tekrar şişlik yakınması ile başvuran, patolojisi servikal kistik lenfanjiom olarak raporlanan erişkin bir hasta sunuldu.

\begin{abstract}
Lymphangiomas are congenital malformations with benign character, affecting the lymphatic channels and generally observed in ages below two years. They most frequently originate from the head and neck region. Although occurrence in adults is rare, it should be considered in the differential diagnosis of cervical masses. Diagnosis is established through anamnesis, physical examination findings and imaging methods. The preferred treatment method is surgery. In this article, we present a 27 -year-old male patient with $13.2 \times 7.6 \times 13 \mathrm{~cm}$ sized mass localized in left cervical region that has been continuing to grow despite being excised before. Ultrasonography and magnetic resonance imaging findings of the mass were compatible with cystic lymphangioma. Therefore, the mass was totally excised. Histopathologic examination was compatible with cystic lymphangioma. No complication was observed in the period after surgery and no recurrence developed during the one-year follow-up.

Keywords: Adult; cervical; cystic lymphangioma.
\end{abstract}

\section{OLGU SUNUMU}

Yirmi yedi yaşındaki erkek hasta boynun sol tarafında şişlik şikayetiyle kliniğimize başvurdu (Şekil 1). Hastanın öyküsünden şikayetlerinin üç yıl önce başladığı, bir yıl önce dış merkezde ilk ameliyatını olduğu, sonucun kistik lenfanjiom olarak rapor edildiği ve son altı aydır aynı bölgede giderek artış gösteren şişlik şikayetinin tekrarladığı öğrenildi. Ayrıca yaklaşık iki ay önce bir sağllk kuruluşunda boyun bölgesindeki şişliğin iki defa enjektör yardımı ile perkütan aspire edilerek boşaltıldığı, patojisinin benign sitoloji olarak raporlandığı öğrenildi.

Geliş tarihi: 20 Haziran 2018 Kabul tarihi: 26 Temmuz 2018

İletişim adresi: Dr. Ozan Erol. Başkent Üniversitesi Tıp Fakültesi, Kulak Burun Boğaz Anabilim Dalı, 06490 Bahçelievler, Ankara, Türkiye. e-posta: ozzy.erol@gmail.com 


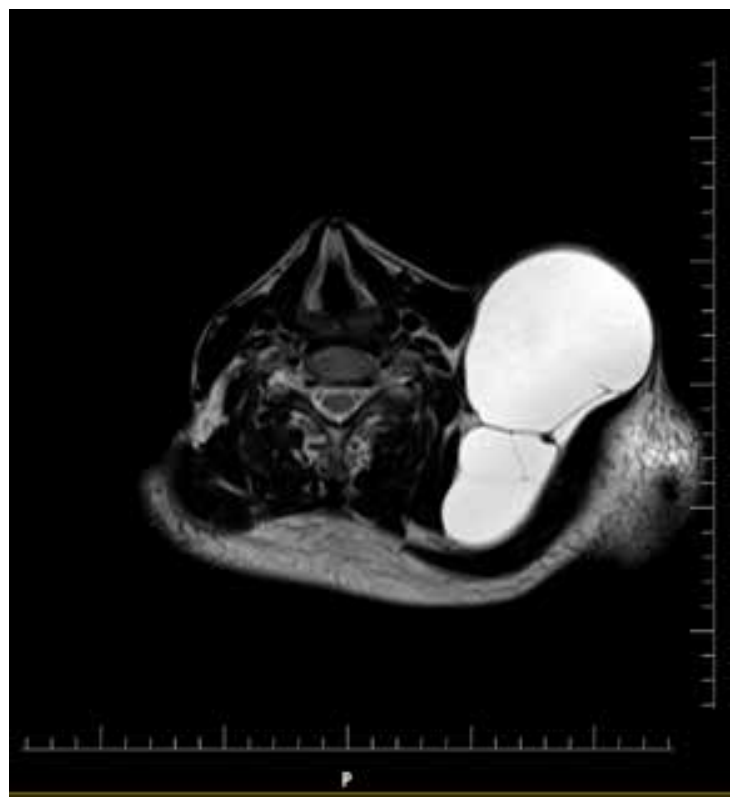

Şekil 1. Sol supraklaviküler bölgede yaklaşık $13 \mathrm{~cm}$ boyutlarında ağrısız, yumuşak, fluktuan kitle.

Fizik muayenesinde boyunda sol supraklaviküler bölgede yaklaşık $15 \mathrm{~cm}$ boyutlarında ağrısız, yumuşak kitle palpe edildi. Yüzeyel doku ultrasonografi (USG)'sinde $13 \times 7 \mathrm{~cm}$ boyutlarında septalı kistik lezyon vard. Manyetik rezonans görüntüleme (MRG)'sinde, solda sternokleidomastoid kas, posterior ve lateralinde trapezius kas anterioruna kadar uzanan, daha inferiorda

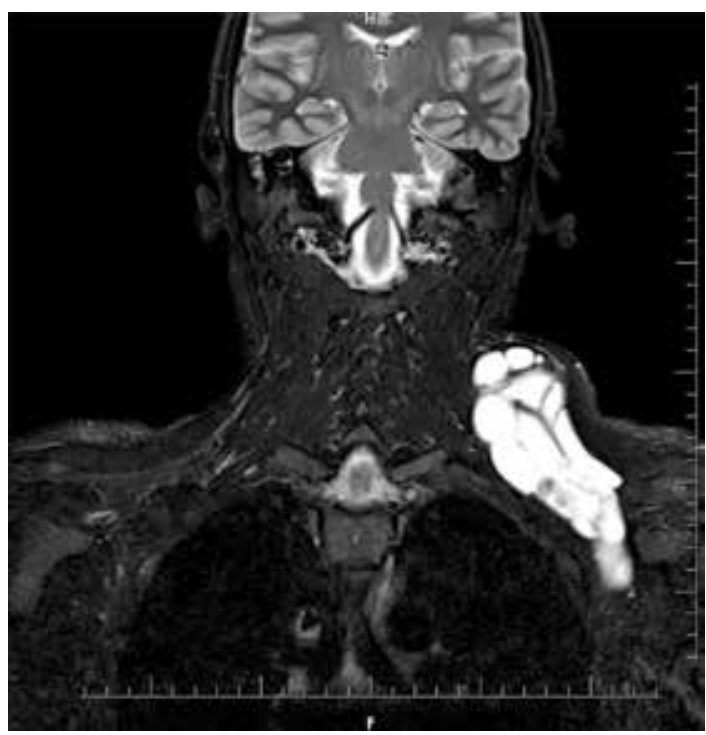

Şekil 2. Kontrastlı koronal boyun manyetik rezonans görüntüleme. Aksiller fossa süperiorunda sonlanan, medialde klavikula inferioruna doğru uzanımı izlenen, septalı kistik lezyon.

supraspinatus kası ile komşuluğu izlenen aksiller fossa süperiorunda sonlanan, medialde klavikula inferioruna doğru uzanımı izlenen, içerisinde septasyonlar bulunan (Şekil 2), $13.2 \times 7.6 \times 13 \mathrm{~cm}$ boyutlarında kistik lenfanjioma ait olduğu düşünülen dev lezyon saptandı (Şekil 3). İnfraklaviküler seviyede brankiyal pleksus lifleri ile temas halinde, supraskapuler siniri sarmış olduğu görüldü.
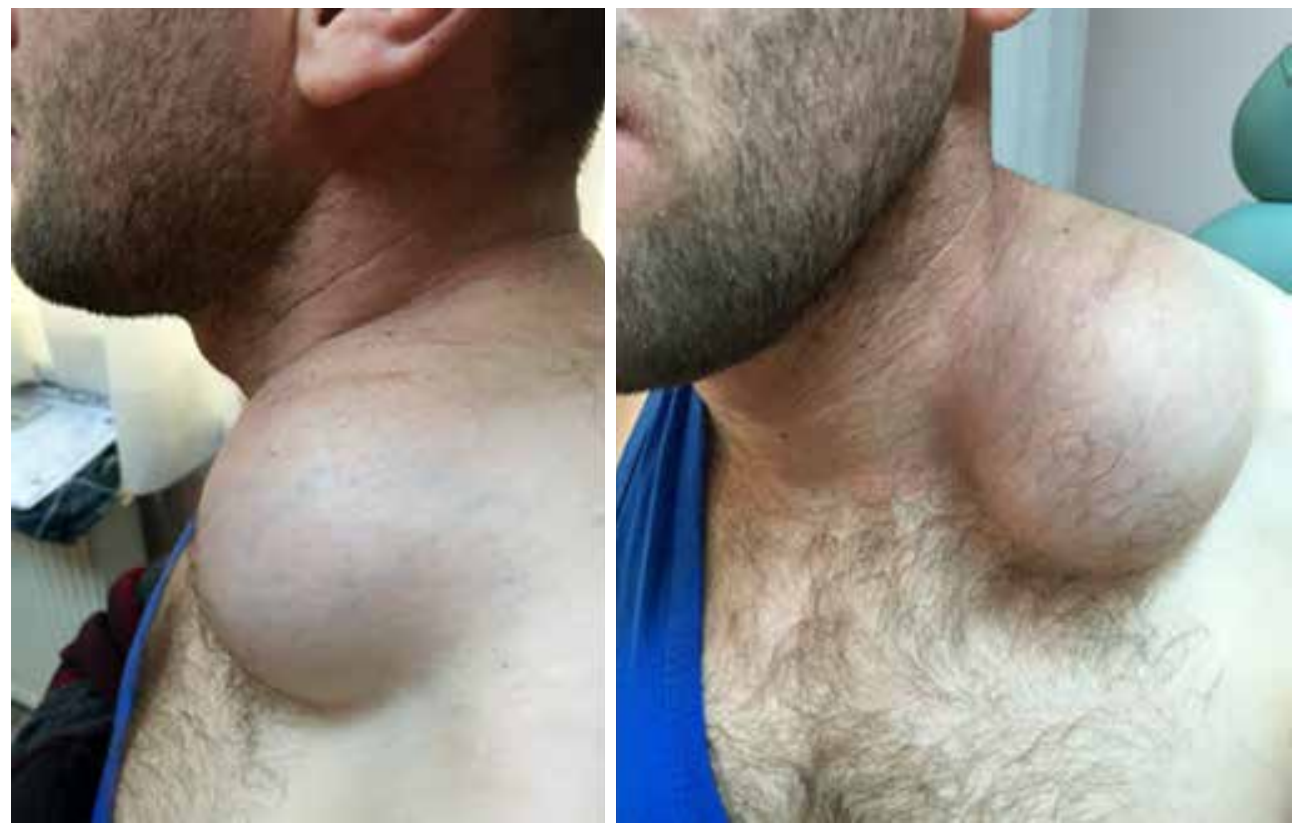

Şekil 3. Kontrastlı aksiyel boyun manyetik rezonans görüntüleme. Sağda sternokleidomastoid kası posteromedialinde kistik lezyon. 


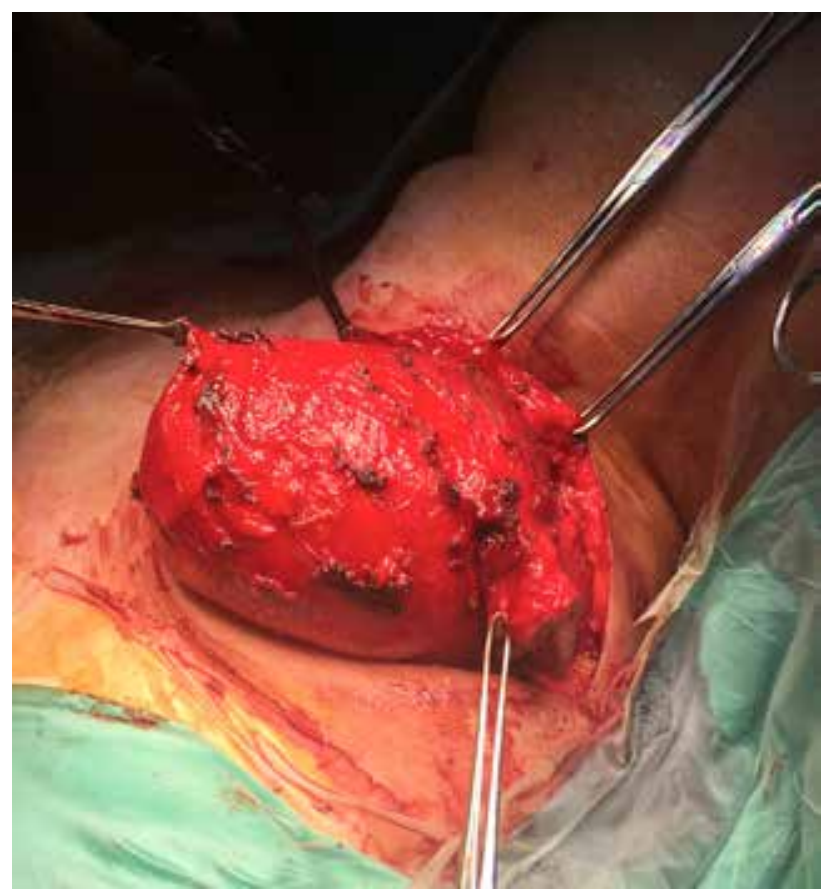

Şekil 4. Kitlenin ameliyat sırası görünümü.

Genel anestezi altında klavikulanın $2 \mathrm{~cm}$ yukarısında tam klavikulaya paralel şekilde $10-12 \mathrm{~cm}$ insizyon yapilarak anteromedialinde eksternal karotisten, anteroinferiorunda klavikula arkasından anteriorda sternokleidomastoid kasından serbestleştirildi. Altında bulunan omohyoid kasa invaze durumda idi. Subklavian arter komşuluğundaki kistin çevresi künt diseksiyonlarla kontrollü bir şekilde dönülerek çevre dokulardan ayrıldı (Şekil 4). Kist klavikula hizasında multiloküle yapıdaydı. Brankiyal pleksus üzerindeki tüm kistik oluşumlar cidar bırakılmadan kapsülleri ile birlikte, pleksusun lifleri korunarak eksize edildi.

Histopatolojik incelemesi kistik lenfanjiom şeklinde rapor edildi. Cerrahi sonrası dönemde hastanın sol kol ve elinde hipoestezi oldu ancak güç kaybı yoktu. Bir hafta sonraki kontrolünde hipoestezi şikayeti tamamen geçen hastanın, bir yıllık takibinde nüks ile karşılaşılmadı.

\section{TARTIŞMA}

Kistik lenfanjioma ilk olarak Redenbacker (1828) tarafından tanımlanmıştır. Wernker (1848) kistik higroma terimini ilk kullanan yazardır. Koester (1872) ise kistik higromanın lenfatik sistemden geliştiğini göstermiştir. ${ }^{[4]}$

Lenfanjiomlar primordial lenf kanallarının gelişiminde doğuştan bir tıkanıklık sonucu ortaya çıktıkları düşünülen doğuştan malformasyonlardır. $\mathrm{Bu}$ lezyonların \%75'i baş boyun bölgesinde yerleşiktir. ${ }^{[4,5]}$ Çoğunlukla infantlarda ya da iki yaşından küçük bebeklerde bulunmaktadır. Erişkin yaşlarda görülmesi beklenmemesine rağmen, bizim 27 yaşındaki hastamızda olduğu gibi erişkin hastalarda da olabilir. Erişkinlerde kistik lenfanjiomun travmaya sekonder olarak da saptanabileceğini bildiren çalışmalar $\operatorname{vard}_{11 .}{ }^{[5,6]}$ Literatürde 100 'den az erişkin servikal lenfanjioma olgusu bildirilmiştir. ${ }^{[7]}$

Hastalar olgumuzda da olduğu gibi genelde yavaş büyüyen, asemptomatik, fluktuan, yumuşak doku kitlesiyle başvururlar. Benign davranışlı oldukları ve yavaş büyüdükleri için genellikle belirti vermezler. Fakat bazen solunum ve yutma güçlüklerine yol açabilirler. Ayrıca hastayı rahatsız edici kozmetik sorunlara da yol açabilirler. Özellikle erişkinlerde görülen lenfanjiomlarda spontan düzelme beklenmediğinden mutlaka tedavi edilmelidir. ${ }^{[7-9]}$ Bunun yanında bazı araştırmacılar lenfanjiomaları lokal agresif davranış gösteren gerçek tümörler olarak değerlendirmekte ve mutlaka eksize edilerek tedavi edilmesini savunmaktadir. ${ }^{[9]}$

Lipom, dermoid kist, brankiyal kist, tiroglossal kist ve hemanjiom gibi boyun kitleleri akla getirildiğinde mutlaka ayırıcı tanı yapılması gerekmektedir. Bu nedenle radyolojik inceleme gerekir. ${ }^{[9-11]}$ Görüntüleme yöntemleri; lezyonun yapısını doğrulamada, ayırıcı tanıda, kitlenin sınırlarını belirlemede ve çevre dokularla olan ilişkisini belirlemede faydalıdır. Kitlenin boyutunu belirlemede MRG hem USG'den hem de bilgisayarlı tomografiden daha doğru bilgi verir. ${ }^{[10,11]}$ Tipik olarak kistlerin çoğu sternokleidomastoid kasın önüne yerleşirken, kistik lenfanjiomlar genellikle olgumuzda da olduğu gibi kasın arkasına yerleşir.

Tedavi amaciyla yapilan drenaj ve aspirasyon gibi yöntemlerde rekürrens oranının yüksek olması nedeniyle bu yöntemlerin etkili ve kesin bir tedavi sağlamadığ1 düşünülmüştür. Ayrıca bu yöntemlerde enfeksiyon riskinin arttı̆̆ını bildiren çalışmalar literatürde mevcuttur. ${ }^{[12]}$

Tedavi amacıyla lezyon içine \%5 dekstroz, kaynar su, sodyum moruat ve bazı sklerozan ajanlar (bleomisin vb.) verilerek denenmiştir. Bu yöntemlerde skar oluşumu, komşu yapılara hasar verebilme ihtimali ve uzak (bleomisin kullanımıla pulmoner fibrozis) yan etkileri bildirilmiştir. Ancak cerrahi olarak tam olarak çıkarılamayan kitlelerde lezyon içi enjeksiyonlar ikinci bir tedavi yöntemi olarak akla getirilmelidir. Ayrıca radyoterapi de tedavi amacıyla kullan1labilmektedir. ${ }^{[12]}$

Kistik lenfanjiomun kesin tedavisi cerrahi eksizyondur. Erişkin hastalarda lenfanjiomdaki kapsül yapısı nedeniyle tam bir eksizyon sağlanabilir. Fakat 
çocuklarda lenfanjiomun tam olarak çıkarılması zordur. Bunun nedeni ise genellikle çocuklardaki kitlenin duvarının ince olması ve çevre dokulara tutulumun fazla olmasıdır. Tam olarak çıkarılmayan olgularda rekürrens olabilmektedir. ${ }^{[1,2,4,7,8,12]}$ Bizim olgumuzda da hastanın daha önce ameliyat olmasına rağmen şikayetinin nüks etmesi, kitlenin tam olarak çıkarılamadığını düşündürdü.

Hastalığın kesin tanısı histopatolojik olarak konur. Histopatolojik incelemede siklıkla lenfanjiomatöz doku ve lenfosit toplulukları ile beraber bir sira yassı endotel tabakasıyla örtülü multilobüle dilate lenf kanalları vardır. Temel olarak lenfanjiomlar, kapiller, kavernöz, kistik olmak üzere üç gruba ayrılır. ${ }^{[13]}$ Bizim olgumuzda kitleye, kistik lenfanjiom tanısı konuldu.

Sonuç olarak lenfanjiomlar lenfatik sistemin nadir görülen, benign, doğuştan lezyonlarıdır. Tanı genellikle çocukluk yaşlarında konulur, fakat her yaşta görülebilir. Erişkin yaşta oldukça nadirdir. Fizik muayene ve öykü, görüntüleme yöntemleriyle desteklenerek tanı konulur. Tercih edilen tedavi yöntemi cerrahidir. Kitle tam olarak çıkarılmalıdır; aksi takdirde rekürrens görülebilir.

\section{Çıkar çakışması beyanı}

Yazarlar bu yazının hazırlanması ve yayınlanması aşamasında herhangi bir çıkar çakışması olmadığını beyan etmişlerdir.

\section{Finansman}

Yazarlar bu yazının araştırma ve yazarlık sürecinde herhangi bir finansal destek almadıklarını beyan etmişlerdir.

\section{KAYNAKLAR}

1. Schefter RP, Olsen KD, GaffeyTA. Cervical lymphangioma in the adult. Otolaryngol Head Neck Surg 1985;93:65-9.

2. Wiggs WJ Jr, Sismanis A. Cystic hygroma in the adult: two case reports. Otolaryngol Head Neck Surg 1994;110:239-41.

3. Kuzgun U, Öztürk I, Tezer M. Kistik lenfanjioma. Acta Orthop Traumatol Turc 1993;27:62-4.

4. Aneeshkumar MK, Kale S, Kabbani M, David VC. Cystic lymphangioma in adults: can trauma be the trigger? Eur Arch Otorhinolaryngol 2005;262:335-7.

5. Gleason TJ, Yuh WT, Tali ET, Harris KG, Mueller DP. Traumatic cervical cystic lymphangioma in an adult. Ann Otol Rhinol Laryngol 1993;102:564-6.

6. Metin B, Kaya S, Sarıçam M, Özkan E, Tözüm H, Aygün B, et al. Cyctic Hygroma in an Adult: Case Report. Bozok Med J 2014;4:66-8.

7. Enzinger FM, Weiss SW, editor. Soft Tissue Tumors. 2nd ed. St Louis: Mosby-Year-Book; 1988.

8. Baer S, Davis J. Cystic hygroma presenting in adulthood. J Laryngol Otol 1989;103:976-7.

9. Romeo V, Maurea S, Guarino S, Sirignano C, Mainenti PP, Picardi M, et al. A case of lower-neck cystic lymphangioma: correlative US, CT and MR imaging findings Quant Imaging Med Surg 2013;3:224-7.

10. Ibrahim M, Hammoud K, Maheshwari M, Pandya A. Congenital cystic lesions of the head and neck Neuroimaging Clin N Am 2011;21:621-39.

11. Alqahtani A, Nguyen LT, Flageole H, Shaw K, Laberge JM. 25 years' experience with lymphangiomas in children. J Pediatr Surg 1999;34:1164-8.

12. Sanlialp I, Karnak I, Tanyel FC, Senocak ME, Büyükpamukçu N. Sclerotherapy for lymphangioma in children. Int J Pediatr Otorhinolaryngol 2003;67:795-800.

13. Mathew M, Dil SK. Adult lymphangioma - a rare entity: a report of two cases. Turk Patoloji Derg 2012;28:80-2. 